\title{
EFFECTS OF TEMPERATURE AND STRAIN RATE ON THE MECHANICAL BEHAVIOR OF A SUPERELASTIC NITI WIRE*
}

\author{
Guilherme Corrêa Soares ${ }^{1}$ \\ Mariana Carla Mendes Rodrigues ${ }^{2}$ \\ Leandro de Arruda Santos ${ }^{3}$
}

\begin{abstract}
The effects of temperature and strain rate on the mechanical behavior of a superelastic $\mathrm{NiTi}$ wire were investigated by uniaxial tensile testing. A universal testing machine with an attached heating chamber was used for the tensile tests. Temperature influence was studied through straining of samples until rupture at a fixed strain rate and temperatures of $25,50,75,100,125,150,175$ and $200{ }^{\circ} \mathrm{C}$. Strain rate effects were investigated by straining samples until rupture at room temperature and strain rates of $10^{-2}, 5 \times 10^{-3}, 10^{-3}, 5 \times 10^{-4}$ and $10^{-4} \mathrm{~s}^{-1}$. The effects of temperature and strain rate on $\mathrm{NiTi}$ mechanical behavior were discussed in terms of critical stress to induce martensite and austenite yield strength, when applicable; upper plateau stress, transformation plateau length and ultimate plateau stress. It was found that increasing test temperature and strain rate shifted the stress-strain curve upwards, albeit temperature displayed a greater influence. Plateau length increased with temperature, but no significant changes were detected as a result of different strain rates.
\end{abstract}

Keywords: NiTi; Mechanical Behavior; Strain Rate; Temperature.

1 Bachelor of Science in Metallurgical Engineering, Master's student, Department of Metallurgical and Materials Engineering, UFMG, Belo Horizonte, MG, Brazil.

2 Bachelor of Science in Materials Engineering, Master's student, Department of Metallurgical and Materials Engineering, UFMG, Belo Horizonte, MG, Brazil.

3 Doctor, Professor, Department of Metallurgical and Materials Engineering, UFMG, Belo Horizonte, MG, Brazil. 


\section{INTRODUCTION}

In recent years, an extensive amount of research has been focused on better understanding the mechanical behavior of near equiatomic NiTi alloys, which exhibit the capacity of recovering from large strains due to their shape memory effect and supereslasticity. NiTi applications range from automotive to the biomedical areas, being a commonly employed material for orthodontic wires, actuators, endodontic files, vascular stents, among others [1-6].

The NiTi superelasticity is closely related to a stress-induced martensitic transformation [5], thus its mechanical behavior depends strongly on testing temperatures $[2,3]$. Several of the NiTi applications must endure cyclic straining and depend on the functional properties stability of the alloy. In order to stabilize their functional properties, NiTi alloys usually undergo a training process, which consists in mechanically or thermically cycling these alloys, so that martensite is deliberately induced several times and a preferable path for the martensitic transformation is achieved [7-9]. Hence, it is of great importance to better understand test parameters in which mechanical training is viable, such as temperature, strain rate and maximum strain amplitude.

Despite some previous studies about the mechanical behavior of superelastic NiTi during uniaxial testing have already been accomplished [1,3-5], limited work has been done in order to investigate the effects of test temperature and strain rate on its mechanical behavior. The complex mechanical behavior of $\mathrm{NiTi}$ is regularly misinterpreted, which can result in inaccurate decisions when choosing a material [6]. The objective of the investigation presented in this paper was to have a better understanding of the relationship between test temperature and strain rate with the mechanical behavior of a superelastic NiTi alloy. In this work, the effects of temperature and strain rate on the mechanical behavior of a NiTi wire in the austenitic condition is investigated through uniaxial tensile testing. The influence of these parameters on the following properties is discussed in this work: critical stress to induce martensite, austenite yield strength, when applicable; upper plateau stress, transformation plateau length and ultimate plateau stress.

\section{MATERIAL AND METHODS}

A NiTi superelastic alloy provided by Nitinol Devices \& Components (Fremont, CA, Unites States) was used in this work. The NiTi wire was received in a cold rolled and annealed condition and specimens with $0.1 \mathrm{~cm}$ diameter were cut into $15.0 \mathrm{~cm}$ total length for tensile testing. A gauge length of $9.0 \mathrm{~cm}$ was measured with the help of a Mitutoyo digimatic caliper (Chicago, IL, USA). Austenite finish temperature $\left(A_{f}\right)$, on the wire as received, was investigated using differential scanning calorimetry (DSC) with a DSC 60 (Shimadzu, Kyoto, Japan) and defined as $7.7^{\circ} \mathrm{C}$. This supports the fact that the wire would present a superelastic behavior when deformed below $\mathrm{Md}_{\mathrm{d}}$ temperature, critical temperature in which dislocation movement becomes preferable to stress induced martensite formation $[9,10]$.

Mechanical behavior and the effects of temperature and strain rate variation on it were investigated through uniaxial tensile tests, which were conducted using an Instron 5582 machine (Instron, Canton, MA, USA) with an environmental test chamber attached. These tensile tests were done in two stages: with a fixed strain rate of $10^{-3} \mathrm{~s}^{-}$ 1 and test temperatures of $25,50,75,100,125,150,175$ and $200^{\circ} \mathrm{C}$; and at room temperature and strain rates of $10^{-4}, 5 \times 10^{-4}, 10^{-3}, 5 \times 10^{-3}$ and $10^{-2} \mathrm{~s}^{-1}$. 
The mechanical behavior results were discussed in terms of critical stress to induce martensite and austenite yield strength, when applicable; upper plateau stress, transformation plateau length and ultimate plateau stress. Critical stress to induce martensite and austenite yield strength were measured through the intercept of a $0.2 \%$ strain offset parallel line with the elastic portion of the curve, as according to reference [3]. The criteria for determining if stress-induced martensite was formed or if austenite was being plastically deformed was the test temperature being above or below $\mathrm{Md}_{\mathrm{d}}$. It was not an objective of this work to establish a precise value of $\mathrm{Md}_{\mathrm{d}}$ temperature, so a temperature range was estimated by the disparity in the mechanical behavior between the tensile tests at different temperatures.

Upper plateau stress was measured as the stress at $3 \%$ strain, as defined by the ASTM F 2516-07 standard [13]. The transformation plateau end point was calculated as the intercept between the stress-strain curve and a $-0.2 \%$ strain offset parallel line with the elastic portion of martensite deformation. The ultimate plateau stress was then determined as the stress in this end point, while the plateau length was calculated by subtracting elastic strain. In order to better elucidate how these parameters were assessed in this work, a schematic stress-strain curve with graphical indications of the parameters is shown in Fig. 1.

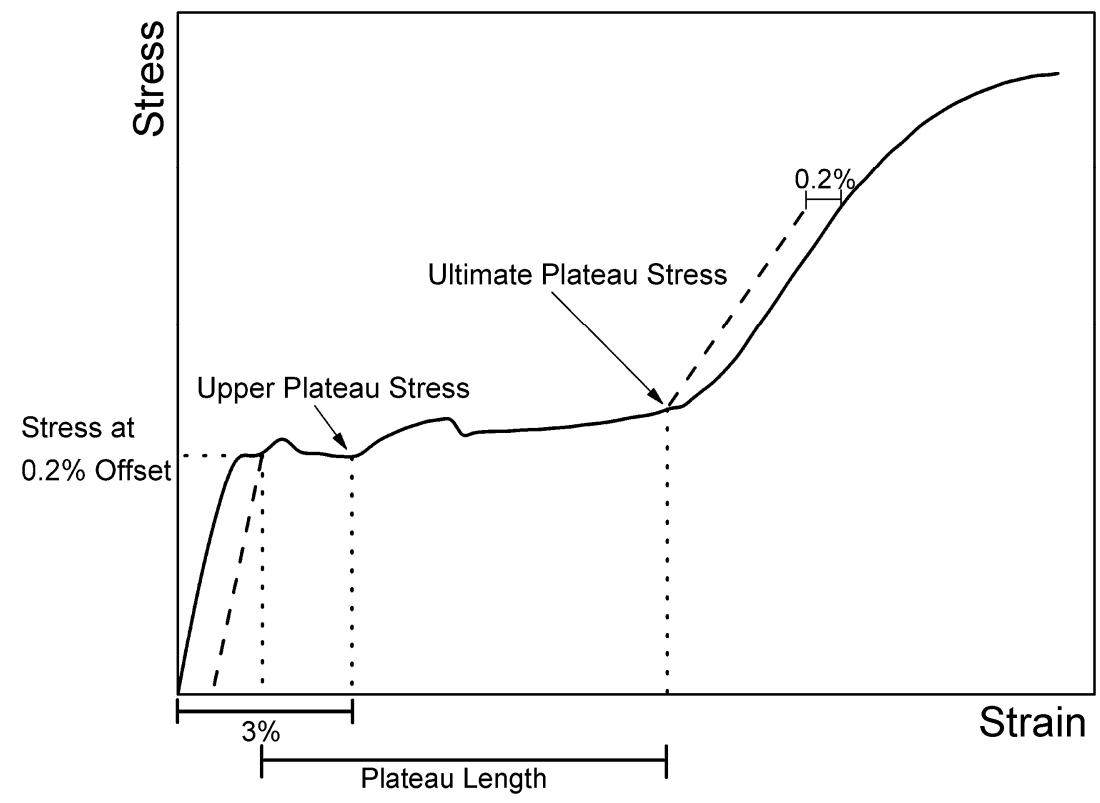

Figure 1. Schematic stress-strain curve with graphical indications of how the studied parameters were assessed in this study.

\section{RESULTS AND DISCUSSION}

The results obtained in this investigation indicated that the mechanical behavior of a superelastic NiTi alloy depends strongly on the deformation temperature and is influenced by the strain rate. Generally, increase in these parameters shifts the curves upwards, which can be explained by the increase in austenite stability and the earlier elastic deformation of martensite. Most of the results found are in agreement with the ones from previous publications [1-10]. 


\subsection{Temperature effects}

The stress-strain curves for the NiTi samples strained at different temperatures and a strain rate of $10^{-3} \mathrm{~s}^{-1}$ are shown in Fig. 2. It is evident that temperature increase causes the stress-strain curves to shift upwards, which is explained by austenite becoming more stable at higher temperatures and requiring a higher stress to induce martensite. Through this analysis, Md temperature was estimated as being in the $150-175^{\circ} \mathrm{C}$ temperature range, due to the clearly visible diminishment in ductility $[9,10]$. Similar behaviors were also found in the literature when estimating $M_{d}$ for other metals, which like $\mathrm{NiTi}$, presented a martensitic transformation during deformation [11,12]. These investigations concluded that above $M_{d}$ temperature, elongation approached the elongation of a severely strain hardened austenite, which corroborates with the results found in the present work.

It was observed that the slope of the portion posterior to the plateau, usually associated with stress-induced martensite elastic deformation, decrease with the increase in temperature, which may be related to inelastic deformation occurring in this stage $[3,14]$. An evident martensite orientation stress-drop occurred only at $25^{\circ} \mathrm{C}$, at a strain of approximately $6 \%$, which could point to the fact that when deformed at higher temperatures, martensite formation is slower and its orientation does not take place [15]. A slightly jagged stress behavior was also noted for the plastic deformation of austenite, at the temperatures of 175 and $200^{\circ} \mathrm{C}$.

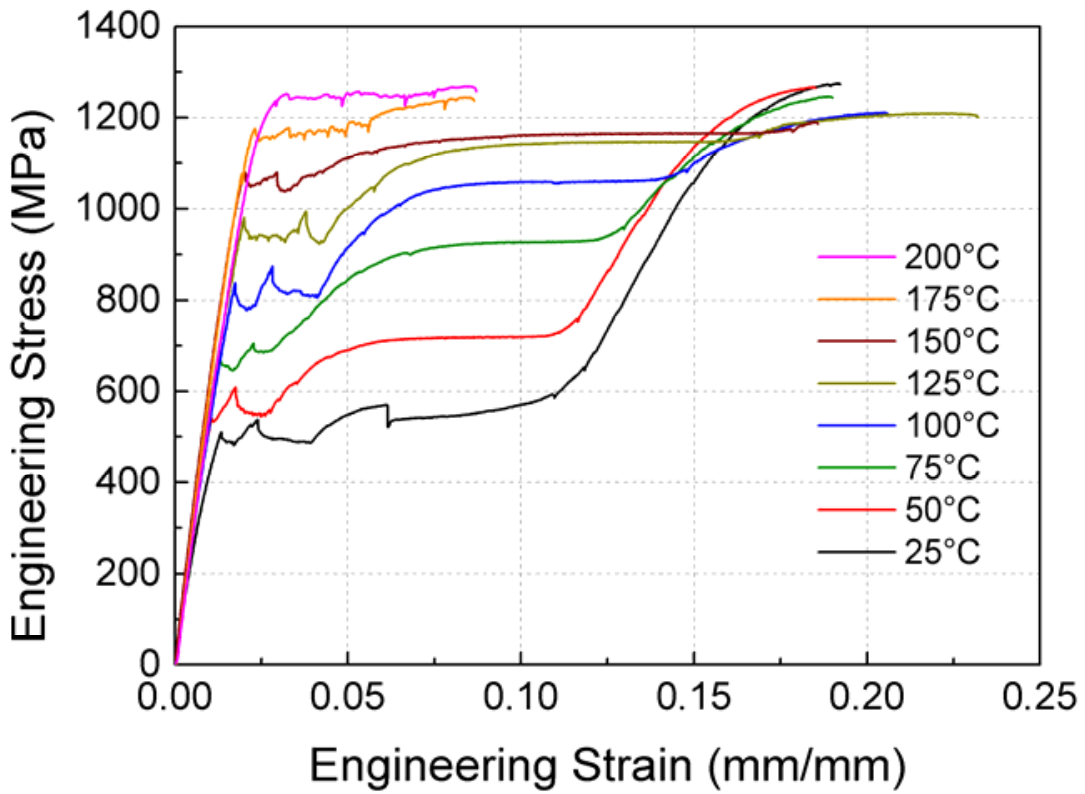

Figure 2. Superelastic NiTi stress-strain curves at different temperatures obtained through tensile testing with help of a heating chamber and at a $10^{-3} \mathrm{~s}^{-1}$ strain rate.

The engineering stress at a $0,2 \%$ offset and at $3 \%$ strain value as a function of test temperature are illustrated in Fig. 3 (a) and (b), respectively. Although, for lower temperature values, those behaviors slightly deviated from what is expected by the Clausius-Clapeyron relationship [16], the relationship between the stress to induce martensite and temperature is fairly linear and is also observed for the upper plateau stress (Fig. 3(b)). It was also observed that the austenite yield strength, regarding the tests at temperatures of 175 and $200{ }^{\circ} \mathrm{C}$, also followed a linear relationship. Yield strength usually decreases as temperature increases [17], so an yield strength anomaly has been observed in the studied temperature range. This anomalous 
temperature dependence of yield strength has also been reported by a previous study, being associated to precipitation hardening and/or some anomaly in dislocation motion [17].
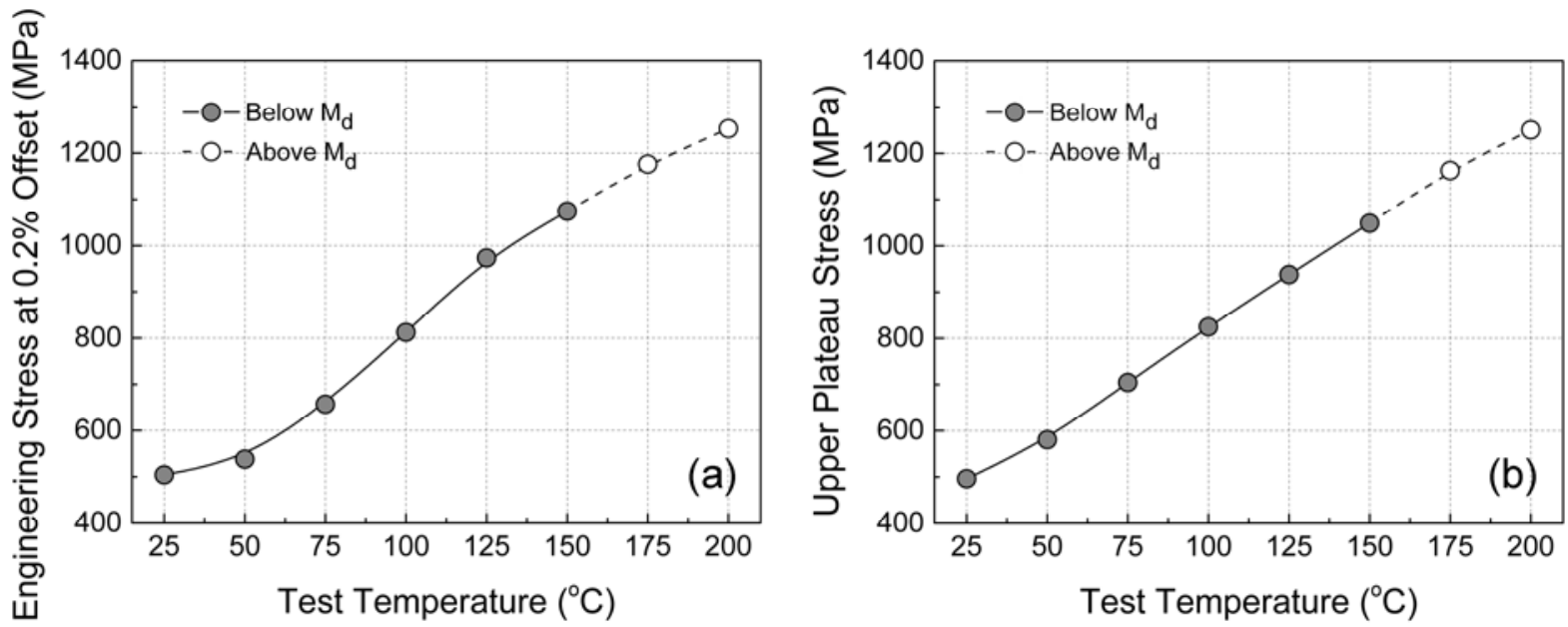

Figure 3. Engineering stress at a $0.2 \%$ offset (a) and upper plateau stress (at $3 \%$ strain) (b) as a function of test temperature. Results are represented as below $M_{d}$ and above $M_{d}$ temperature.

As the stress-strain curves are shifted upwards with an increase in test temperature, a similar behavior is also expected for the ultimate plateau stress. Ultimate plateau stress and transformation plateau length as function of test temperature is shown in Fig. 4 (a) and (b), in this order. These results are only represented until $150{ }^{\circ} \mathrm{C}$ due to the absence of a transformation plateau after $\mathrm{M}_{\mathrm{d}}$. Ultimate plateau stress rises steeply from $25{ }^{\circ} \mathrm{C}$ to $100{ }^{\circ} \mathrm{C}$, having the temperature a lower influence after that point. The transformation plateau length is virtually constant at lower temperatures (25 and 50 $\left.{ }^{\circ} \mathrm{C}\right)$, showing a noticeable ascending behavior with temperature increase, which was explained in a previous publication as the result of additional inelastic mechanisms being activated [3].
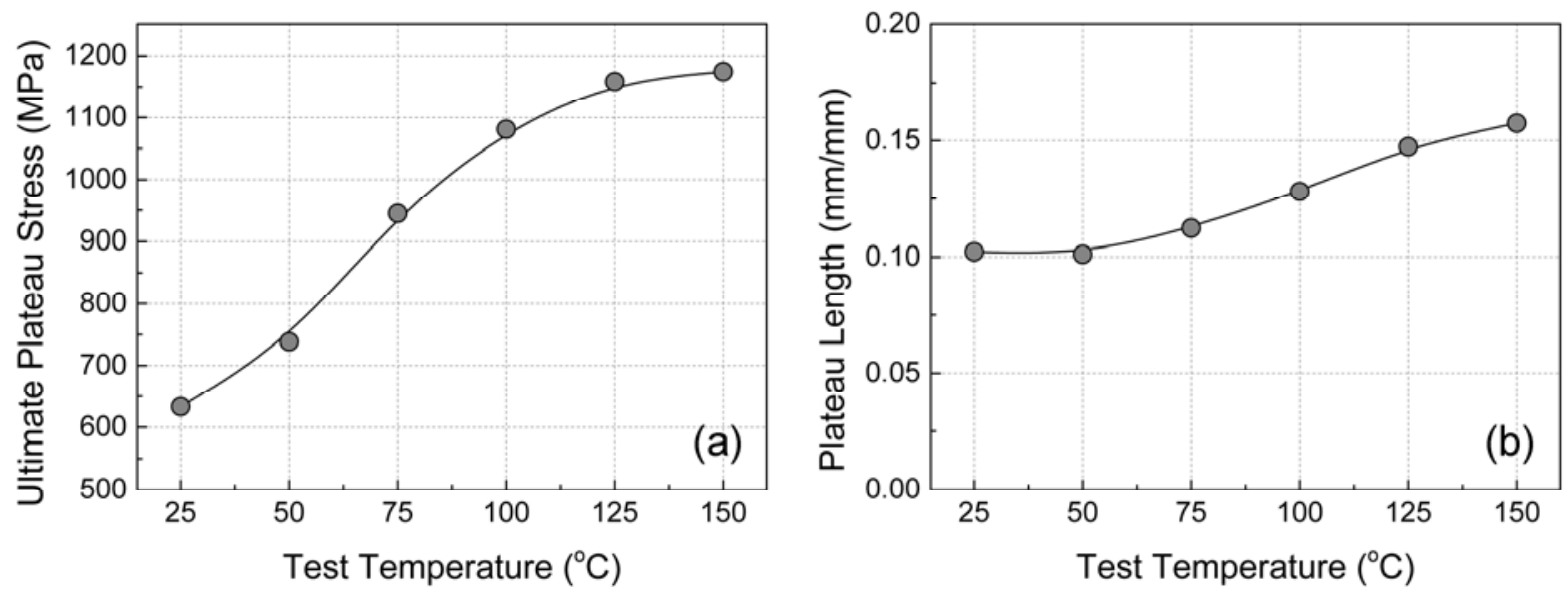

Figure 4. Ultimate plateau stress (a) and transformation plateau length (b) as a function of test temperature. Results are represented until $150^{\circ} \mathrm{C}$ due to the absence of a transformation plateau after Md. 


\subsection{Strain rate effect}

The stress-strain curves for the NiTi samples strained at room temperature and different strain rates are shown in Fig.5. As a result of the curves often superposing in a simple stress-strain graph, these curves had to be represented in a cascade plot in order to put the plateau profile evolution in evidence. The cascade plot makes it evident, that the plateau profile changes from a flat and without martensite orientation stress drops profile at lower strain rates, to a serrated profile with several martensite orientation stress drops at higher strain rates. These results are consistent with previous studies, in which the lack of martensite orientation for lower strain rates was associated with there being enough time for the microstructure to rearrange itself and not enough stress being built up between the interfaces to cause an orientation. The serrated profile for higher strains was explained as the result of the interfaces between martensite and austenite not having enough time to rearrange, causing the internal stress to rise and martensite orientation to occur $[2,5,6]$.

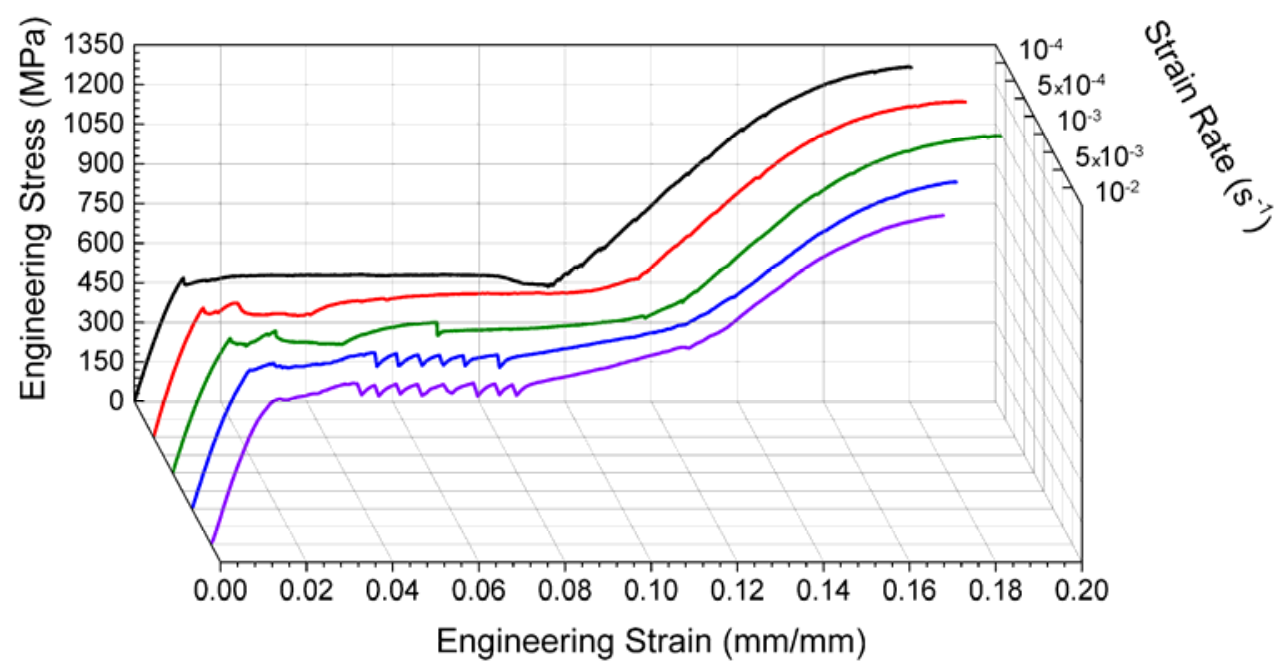

Figure 5. Superelastic NiTi stress-strain curves at different strain rates performed at room temperature. The plateau evolution from a linear to a serrated profile is evident with the increase in strain rate.

The influence of strain rate on the mechanical behavior of $\mathrm{NiTi}$ is significantly lower than that of temperature, in the studied range of these two parameters. Although the stress-strain curve is also shifted up with an increase in strain rate, this increment is diminished, when compared with test temperature influence. Previous investigations have pointed out that the increase in strain rate would also lead to a higher specimen's temperature, due to there not being enough time for the heat generated by martensite transformation and plastic deformation to dissipate [6,9]. One of these studies have shown that samples in tensile testing conducted in air at strain rates of $10^{-4}, 10^{-3}$ and $10^{-2} \mathrm{~s}^{-1}$ can have an increase in temperature of 6,11 and $28^{\circ} \mathrm{C}$, respectively [9]. Therefore, specimen's temperature change also plays a role in NiTi's mechanical behavior when deformed in a gaseous environment and probably influenced in the strain rate analysis results. Critical stress to induce martensite and upper plateau stress as function of test strain rate are represented in Fig. 6 (a) and (b), respectively. In spite of those parameters exhibiting similar values, they display different behaviors with an increase in strain rate. While the critical stress to induce martensite rises at the first half of the graph and stabilizes at higher strain rates, upper plateau stress is fairly constant at lower strain rates and rises for higher strain rates. These results are in 
accordance with what was concluded in past studies, in which an increase of yield strength with strain rate was verified $[2,6]$
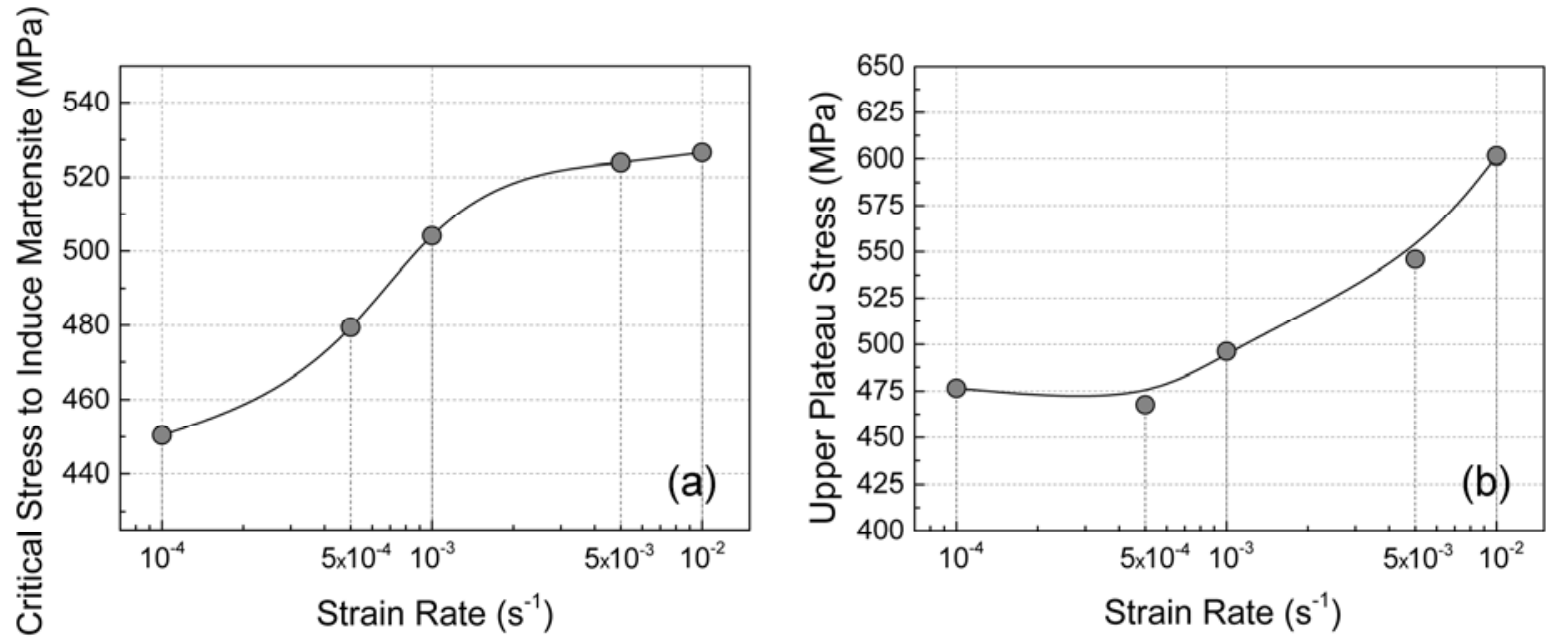

Figure 6. Critical stress to induce martensite (a) and upper plateau stress (at $3 \%$ strain) (b) as a function of test strain rate.

With an increase in strain rate, it is also clearly visible that the final portion of the transformation plateau tilts up, being reasonably slant in relation to the horizontal direction (see also Fig. 5). This vertical translation of the rear portion of the transformation plateau is also shown on the plot of ultimate plateau stress as a function of test strain rate in Fig. 7(a). This behavior was also observed in previous studies and was associated to the stress-induced martensite formation not being able to cope with such high strain rates, thus occurring both martensite formation and martensite elastic deformation simultaneously on this segment $[2,6]$. The influence of strain rate in the transformation plateau length appears to be minor, being practically constant for the studied strain rate range, as shown in Fig. 7(b).
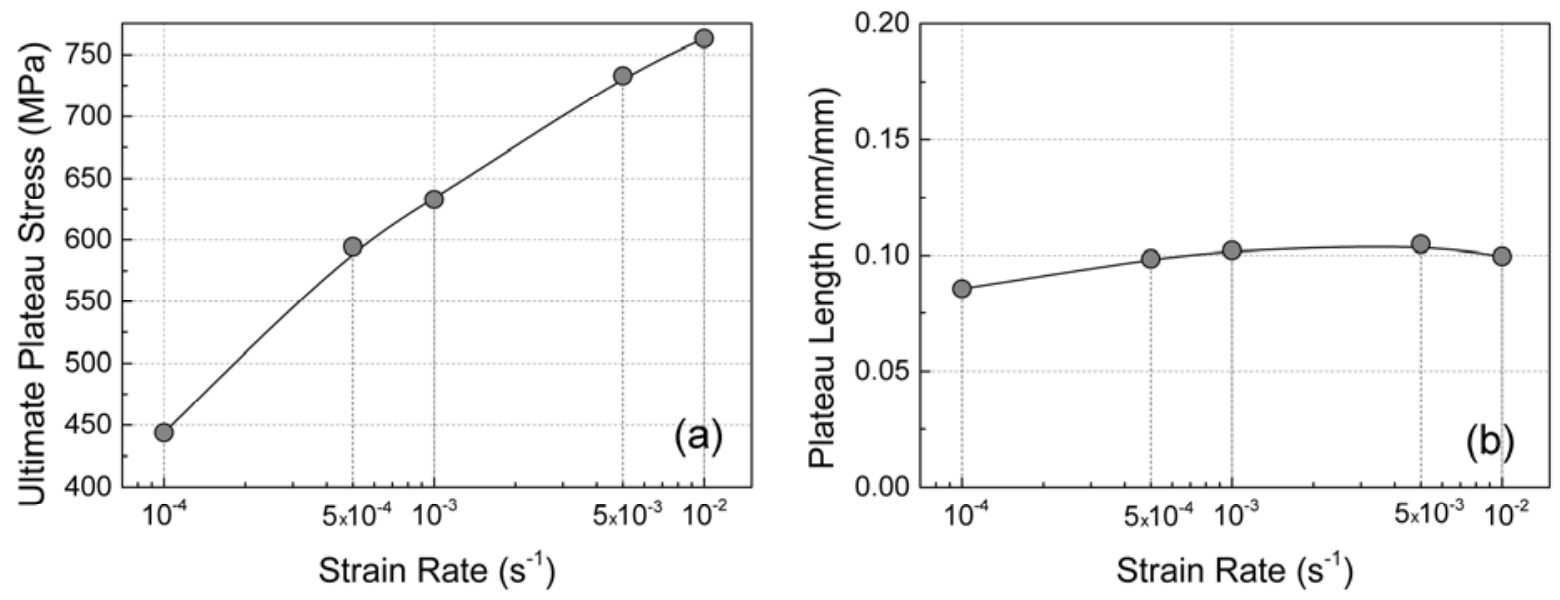

Figure 7. Ultimate plateau stress (a) and transformation plateau length (b) as a function of test strain rate. 


\section{CONCLUSIONS}

In this work, the influence of temperature and strain rate on the mechanical behavior of a superelastic NiTi wire was studied through uniaxial tensile testing. The conclusions derived from the investigation can be summarized as the following:

1. The increase in test temperature shifted the stress-strain curve upwards. The critical stress to induce martensite increased as a result of the austenitic phase being more stable. Md was estimated as being in between $150{ }^{\circ} \mathrm{C}$ and $175^{\circ} \mathrm{C}$, due to the notable diminishment in total strain. In temperatures superior to $\mathrm{Md}_{\mathrm{d}}$ an anomalous yield strength behavior was observed, since yield strength also grew with temperature.

2. Ultimate plateau stress and plateau length also increased with temperature, presumably due to additional inelastic mechanisms being activated. The activation of these extra inelastic mechanisms is, possibly, also responsible for the increase in the slope of the second linear portion of the stress-strain curve.

3. The transformation plateau exhibits a flat profile for low strain rates $\left(10^{-4} \mathrm{~s}^{-1}\right)$ and it becomes serrated with higher strain rates $\left(5 \times 10^{-3}-10^{-2} \mathrm{~s}^{-1}\right)$. Its slope increased at higher strain rates, which lead to higher ultimate plateau stresses, possibly due to the simultaneous occurrence of martensitic transformation and stress induced martensite elastic deformation at such high strain rates.

4. Critical stress to induce martensite and upper plateau stress increased with strain rate. Although temperature contribution at higher strain rates was not assessed in this work, evidences suggest that it might be responsible for some of the mechanical behavior changes which were observed.

\section{Acknowledgments}

The authors gratefully acknowledge support from Coordenação de Aperfeiçoamento de Pessoal de Nível Superior (CAPES/PROEX), Pró-Reitoria de Extensão da Universidade Federal de Minas Gerais (PRPq-UFMG), Conselho Nacional de Desenvolvimento Científico e Tecnológico (CNPq) and Fundação de Amparo à Pesquisa do Estado de Minas Gerais (FAPEMIG).

\section{REFERENCES}

1 Melton, K.N. Mercier, O. The mechanical properties of NiTi-based shape memory alloys. Acta Metallurgica. 1980; 29: 393-398

2 Dayananda, G. N.; Rao, M. S. Effect of strain rate on properties of superelastic NiTi thin wires. Materials Science and Engineering A. 2008; 486: 96-103.

3 Gall, K.; Tyber, J.; Brice, V.; Frick, C. P.; Maier, H. J.; Morgan, N. Tensile deformation of NiTi wires. Journal of Biomedical Materials Research Part A. 2005; 75(4): 810-823.

4 Adler, P.H. Yu, W. Pelton, A.R. Zadno, R. Duerig, T.W. Barresi, R. On the tensile and torsional properties of pseudoelastic NiTi. Scripta Metallurgica et Materialia. 1990; 24: 943-970

5 Melton, K.N. Mercier, O. Deformation Behavior of NiTi-Based Alloys. Metallurgical Transactions A. 1978; 9A: 1487-1488

6 Tobushi, H.; Shimeno, Y.; Hachisuka, T.; Tanaka, K. Influence of strain rate on superelastic properties of TiNi shape memory alloy. Mechanics of Materials. 1998; 30: 141-150. 
7 Miyazaki, S.; Imai, T; Igo, I; Otsuka, K. Effect of cyclic deformation on the pseudoelasticity characteristics of Ti-Ni alloys. Metallurgical Transactions A. 1986; 17: 115-120.

8 Miller, D. A.; Lagoudas, D. C. Influence of cold work and heat treatment on the shape memory effect and plastic strain development of NiTi. Materials Science and Engineering A. 2001; 308: 161-175.

9 Shaw, J.A. Kyriakides, S. Thermomechanical aspects of NiTi. Journal of the Mechanics and Physics of Solids. 1995; 43: 1243-1281

10 Melling, T.R. Ødegaard, J. The effect of short-term temperature changes on superelastic nickel-titanium archwires activated in orthodontic bending. American Journal of Orthodontics and Dentofacil Orthopedics. 2001; 119: 263-273

11 Sugimoto, K.I. Kobayashi, M. Hashimoto, S.I. Ductility and strain-induced transformation in a high-strength transformation-induced plasticity-aided dual-phase steel. Metallurgical Transacations A. 1992; 23A: 3085-3091

12 Chanani, G.R. Zackay, V.F. Parker, E.R. Tensile properties of 0.05 to 0.20 Pct TRIP Steels. Metallurgical Transaction. 1971; 2: 133-139

13 ASTM International. F 2516-07; Standard Test Method for Tension Testing of NickelTitanium Superelastic Materials. West Conshohocken, USA : 2008. p. 6

14 Mirzaeifar, R. Gall, K. Zhu, T. Yavari, A. DesRoches, R. Structural transformations in NiTi shape memory alloy nanowires. Journal of applied physics. 2014; 115

15 Liu, Y. Xie, Z. Van Humbeeck, J. Delaey, L. Asymmetry of stress-strain curves under tension and compression for NiTi shape memory alloys. Acta matter. 1998; 46: 43254338

16 Otsuka, K. e Wayman, C. M. Shape memory materials. New York : Cambridge, 1998.

17 Hosoda, H. Mishima, Y. Suzuki, T. Anomalous temperature dependence of yield stress and work haderning coefficient of B2-stabilized NiTi alloys. MRS Online Proceeding Library. 1995. 